\title{
Toughening mechanisms in elastomer-modified epoxies
}

\section{Part 3 The effect of cross-link density}

\author{
R. A. PEARSON, A. F. YEE \\ Department of Materials Science and Engineering, University of Michigan, Dow Building, \\ Ann Arbor, Michigan 48109-2136, USA
}

The role of matrix ductility on the toughenability and toughening mechanism of elastomermodified, diglycidyl ether of bisphenol A (DGEBA)-based epoxies is investigated. Matrix ductility is varied by using epoxide resins of varying epoxide monomer molecular weights. These epoxide resins are cured using 4,4' diaminodiphenyl sulphone (DDS) and, in some cases, modified with $10 \mathrm{vol} \%$ carboxyl-terminated copolymer of butadiene and acrylonitrile (CTBN). Fracture toughness values for the neat epoxies are found to be almost independent of the monomer molecular weight of the epoxide resin used. However, the fracture toughness of the elastomer-modified epoxies is found to be very dependent upon the epoxide monomer molecular weight. Tensile dilatometry indicates that the toughening mechanism, when present, is similar to the mechanism found for piperidine cured, elastomer-modified epoxies studied previously. Scanning electron microscopy and optical microscopy techniques corroborate this finding.

\section{Introduction}

In our previous papers $[1,2]$ the micromechanical deformation mechanisms that contribute to the toughness of elastomer-modified epoxies were described. We concluded that the role of the rubber particles in toughened epoxies is to relieve the constraint in the matrix by cavitating which, in turn, promotes the formation of shear bands in the matrix. The combination of these two processes produces a process zone ahead of the crack tip, which effectively blunts the sharp crack and results in increased toughness. This conclusion is consistent with those reached by Bascom and co-workers [3,4] and Kinloch and co-workers [5-7]. This deduction is also qualitatively similar to the toughening mechanism in those thermoplastic materials which do not readily craze. A schematic illustration of this toughening mechanism is shown in Fig. 1.

Not all epoxies can be toughened to significant extents by elastomeric modification. Meeks [8] has shown that the toughness enhancement obtained by elastomeric modification of epoxy resins is dependent on the structure of the curing agent. This dependence may actually reflect varying degrees of cross-link density. Several others [9-12] have come to similar conclusions: that the fracture toughness of neat epoxies decreases as the cross-link density increases. High cross-link density has been cited as the reason for the lack of toughness enhancement in some elastomermodified epoxies [8].

Modifying the matrix to enhance the toughenability appears to be reasonable because our previous work has identified the matrix as the major energy-absorb- ing component. For a given volume fraction of elastomer, contributions from voiding and stretching of rubber particles should be a more or less constant, small fraction of the total energy absorbed. More specifically, the ability of the matrix to form shear bands, i.e. matrix toughenability, should be directly related to the amount of energy it can dissipate. Furthermore, the reduction of cross-link density should result in increased ductility because ductile deformation requires large-scale cooperative conformational rearrangements of the polymeric backbone. Consequently, the elastomer-modified ductile epoxy can be expected to exhibit enhanced toughness. We also note that Evans et al. [13] proposed that "crack bridging" by the elastomeric particles can have a multiplicative effect on the toughness contribution from matrix deformation. If so, then modifying the matrix would still be a useful means of obtaining high toughness.

The purpose of this work was to investigate the role of the matrix on the micromechanical deformation mechanisms of these complex materials. Tensile dilatometry experiments were performed to identify the micromechanical deformation mechanisms. Fracture mechanics (FM) methods are applied to assess the fracture toughness and several microscopy techniques are employed to examine the nature of the process zones in these FM specimens.

\section{Experimental approach}

\subsection{Materials}

The materials used in this investigation consisted of several diglycidyl ethers of bisphenol A (DGEBA)- 

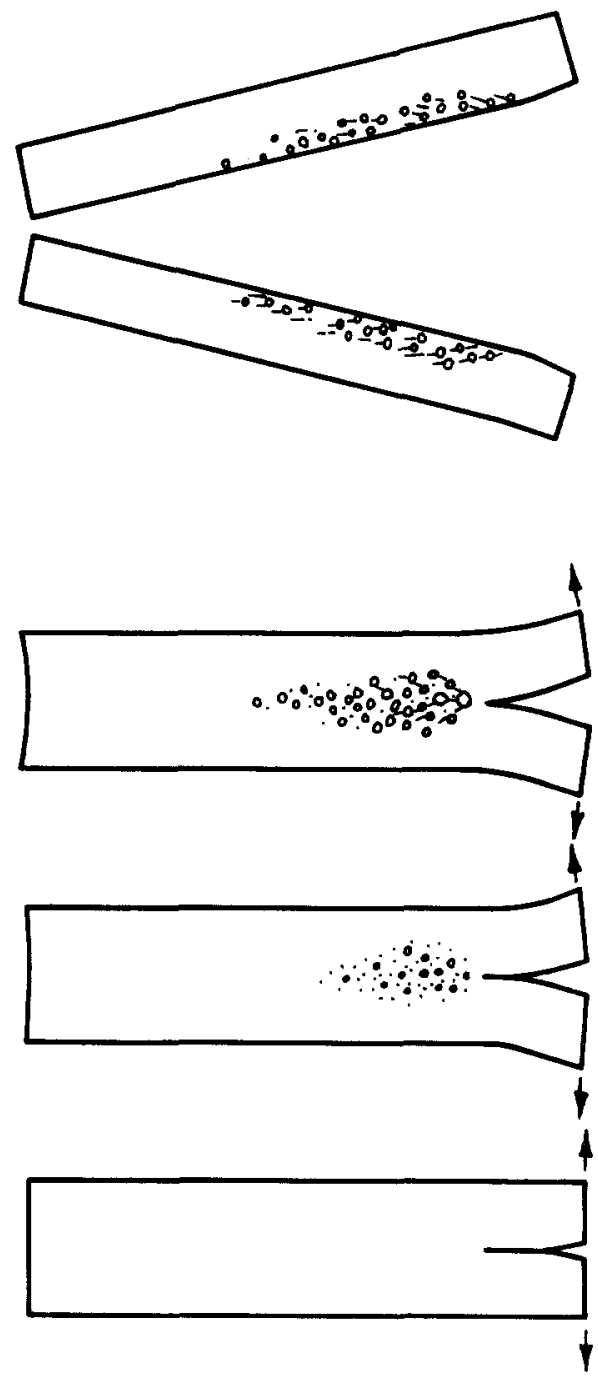

Figure 1 A schematic drawing of the toughening mechanism in rubber-toughened epoxies. based epoxide resins cured using stoichiometric amounts of 4,4'-diamino diphenyl sulphone (DDS). These resins were also modified with $10 \mathrm{vol} \%$ of a carboxyl-terminated copolymer of butadiene and acrylonitrile (CTBN). The chemical structures of these materials are shown in Fig. 2.

The DGEBA epoxide resins are commercial resins produced by the Dow Chemical Company. The manufacturer's description of these DGEBA epoxide resins is listed in Table I. These DGEBA epoxide resins vary in epoxide equivalent weight and are used to control the molecular weight between cross-links (effectively the cross-link density).

The curing agent, DDS (RSA Corp.), was used as-received. DDS was chosen because its curing mechanism is predominantly by amine addition.

The CTBN was supplied by the B.F Goodrich Company and is also commercially available. Three Hycar ${ }^{\circledR}$ CTBN products were described in Part 1 [1]. The Hycar ${ }^{\circledR}$ CTBN $1300 \times 13$ resin was chosen for this work because the use of this CTBN resulted in the formation of rubber particles 1 to $10 \mu \mathrm{m}$ diameter in the DGEBA/DDS materials. The epoxy formulations are given in Table II.

\subsection{Cure schedules}

The epoxide resins used in this work ranged in epoxide equivalent weight from 174 to $1800 \mathrm{~g}$ per equivalent and can be found in either a liquid or solid form at room temperature (depending upon the epoxide equivalent weight, see Table I). This fact forced the adoption of three procedures for the preparation of cured epoxy plaques as shown in Table III. These curing schedules are modifications of those published by Lee and Neville [14]. The reasoning for the<smiles>CC(C)(CC(O)COc1ccc(C2(C)CCCC2)cc1)c1ccc(OCC2CO2)cc1</smiles>

DGEBA resin<smiles>Nc1ccc(S(=O)(=O)c2ccc(N)cc2)cc1</smiles>

DDS (curing agent)

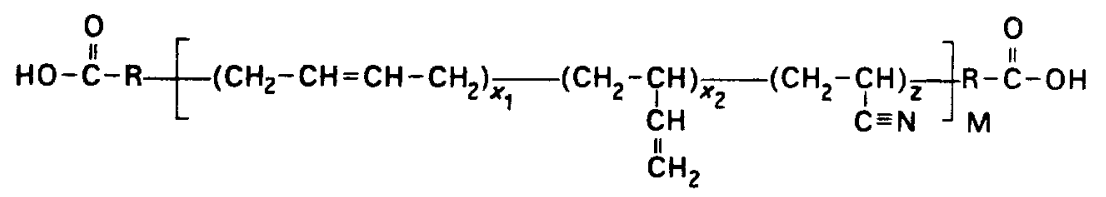


TABLE I Commercial data of epoxy resins given by the Dow Chemical Co.

\begin{tabular}{lcccc}
\hline $\begin{array}{l}\text { DGEBA } \\
\text { resin }\end{array}$ & $\begin{array}{l}\text { Epoxide equivalent } \\
\text { weight (g/eq.) }\end{array}$ & $n^{*}$ & $\begin{array}{l}\text { Viscosity } \\
\text { (or Duran's m.p.) }\end{array}$ & $\begin{array}{l}\text { Specific gravity } \\
\left(\mathrm{g} \mathrm{m}^{-1}\right)\end{array}$ \\
\hline DER 332 & $172-176(174)$ & 0 & $40-50 \mathrm{P}$ & 1.16 \\
DER 337 & $230-250(240)$ & 0.42 & Viscous & 1.16 \\
DER 661 & $475-575(525)$ & 2.2 & $70-80^{\circ} \mathrm{C}$ & 1.18 \\
DER 662 & $575-700(638)$ & 3.0 & $80-90^{\circ} \mathrm{C}$ & 1.18 \\
DER 664 & $875-975(925)$ & 4.8 & $95-105^{\circ} \mathrm{C}$ & 1.18 \\
DER 667 & $1600-2000(1800)$ & 10 & $115-130^{\circ} \mathrm{C}$ & 1.18 \\
\hline
\end{tabular}

$*_{n}$ is the number of DGEBA repeat units calculated from $n=(\mathrm{MW}-348) / 315$.

modifications is as follows. The temperatures for mixing and degassing were chosen based on complex viscosity measurements because a viscosity less than $100 \mathrm{~Pa}$ sec appears to facilitate mixing and suggests that the migration of the DDS will be similar (i.e. diffusion controlled). The duration of the mixing and degassing cycle is dependent upon the time necessary to dissolve the DDS (powder). Note that the DER 332/DDS and DER 337/DDS epoxies required a higher post-curing temperature because their $T_{\mathrm{g}} \mathrm{s}$ are greater than $200^{\circ} \mathrm{C}$. Also, a shorter mould was used for the DER 664 and DER 667 resins because these resins were still rather viscous above $160^{\circ} \mathrm{C}$. A more detailed description of the equipment used to prepare cured epoxy plaques can be found in Part 1 [1].

\subsection{Determination of cross-link density}

The effective cross-link density may be assessed by the determination of molecular weight between crosslinks. Two methods are used to determine the molecular weights between cross-links: the first employs an equation from the theory of rubber elasticity; the second uses an empirical relation developed by Nielsen [15]. A brief description of these methods is presented in the following paragraphs.

In principle, the molecular weight between crosslinks may be determined using an equation from the theory of rubber elasticity [16]:

$$
M_{\mathrm{nc}}=q \varrho R T / G_{\mathrm{c}}
$$

where $M_{\mathrm{nc}}$ is the number average molecular weight between cross-links, $q$ is the front factor (usually equal to 1$), \varrho$ is the density of temperature $T, T$ is the temperature $(\mathrm{K}), G_{\mathrm{c}}$ is the equilibrium modulus in the rubbery region at temperature $T$, and $R$ is the universal gas constant. $G_{\mathrm{c}}$ can be determined from dynamic mechanical measurements. Dynamic mechanical data were obtained using a Rheometrics Mechanical Spectrometer equipped with a torsional fixture for solids.

TABLE II Epoxy formulations used in this investigation

\begin{tabular}{lllll}
\hline Grade resin & $n$ & $\begin{array}{l}\text { Mass } \\
\text { resin }(\mathrm{g})\end{array}$ & $\begin{array}{l}\text { Mass } \\
\text { DDS }(\mathrm{g})\end{array}$ & $\begin{array}{l}\text { When modified } \\
\text { mass CTBN }(\mathrm{g})\end{array}$ \\
\hline DER 332 & 0 & 500 & 189.3 & 60.3 \\
DER 337 & 0.42 & 500 & 133.3 & 56.3 \\
DER 332/667 & 1.0 & $450^{*}$ & 89.3 & 51.8 \\
DER 661 & 2.2 & 500 & 61.0 & 49.9 \\
DER 662 & 3.0 & 500 & 50.0 & 49.1 \\
DER 664 & 4.8 & 500 & 34.6 & 47.9 \\
DER 667 & 10 & 500 & 17.8 & 46.6 \\
\hline
\end{tabular}

*This formulation is a blend of DER 332 and DER 661 resins $(43.3 \mathrm{~g}+406.7 \mathrm{~g})$
Complex shear moduli were measured in oscillating torsion at a frequency of $1 \mathrm{~Hz}$ and with a maximum strain amplitude ranging from 0.4 to $1.6 \%(0.4 \%$ in the glassy state and $1.6 \%$ in the rubber state). Samples $(12.7 \mathrm{~mm} \times 3.2 \mathrm{~mm} \times 50 \mathrm{~mm})$ were heated in a nitrogen atmosphere from room temperature to $50^{\circ} \mathrm{C}$ above $T_{\mathrm{g}}$ using $5^{\circ} \mathrm{C}$ steps with a $5 \mathrm{~min}$ dwell time, at the end of which $G^{\prime}, G^{\prime \prime}$, and $\tan \delta$ were determined. The cross-head of the spectrometer was adjusted to avoid buckling of the specimen in the $T_{\mathrm{g}}$ regime. Unfortunately, only the density at room temperature $\left(1.2 \mathrm{~g} \mathrm{~cm}^{-3}\right)$ was measured. Therefore, a front factor $q$ of 0.725 was required to obtain reasonable values of $M_{\text {nc }}$ (see Section 3).

Because the objective of this work was not to determine the $M_{\mathrm{nc}}$ with a high degree of accuracy but to produce several epoxies with a systematic change in cross-link density, an empirical determination of the $M_{\mathrm{nc}}$ should suffice. The $M_{\mathrm{nc}}$ has been empirically related to $T_{\mathrm{g}}$ by Nielsen [15]. He suggested that the $M_{\mathrm{nc}}$ can be roughly estimated by the use of the following relationship

$$
T_{\mathrm{g}}-T_{\mathrm{go}}=3.9 \times 10^{4} / M_{\mathrm{nc}}
$$

where $T_{\mathrm{go}}$ is the glass transition of the corresponding linear polymer. Bellenger et al. [17] have quoted $364 \mathrm{~K}$ as the value of $T_{\mathrm{go}}$ for DGEBA/DDS materials.

Glass transition temperatures were determined using differential scanning calorimetry (DSC). A Perkin-Elmer model IIA DSC was used. Measurements were performed on $10 \mathrm{mg}$ samples using a scanning rate of $10^{\circ} \mathrm{C} \mathrm{min}^{-1}$. Mid-point $T_{\mathrm{g}}$ values are reported.

\subsection{Fracture toughness assessment}

The fracture toughness of several neat epoxy resins and several corresponding elastomer-modified resins were measured in terms of a critical strain energy release rate $\left(G_{\mathrm{IC}}\right)$. $G_{\mathrm{IC}}$ values were determined using single-edge notched (SEN) specimens (approximately $63.5 \mathrm{~mm}$ long $\times 12.7 \mathrm{~mm}$ wide $\times 6.1 \mathrm{~mm}$ thick) fractured in three-point bending with a span of $50.8 \mathrm{~mm}$. $G_{\mathrm{IC}}$ were determined using the following relationship [18-20]

$$
U=G_{\mathrm{IC}} B D \phi
$$

where $U$ is the stored elastic energy, $B$ is the specimen thickness, and $D$ is the specimen width. The function $\phi$ relates the change in compliance $(C)$ with the change in crack length $(a)$ and is expressed 
TABLE III The three procedures for the preparation of cured epoxy plaques

\begin{tabular}{|c|c|c|c|c|c|c|c|c|}
\hline \multirow[t]{2}{*}{ Resin: } & \multicolumn{2}{|c|}{ Preheating cycle } & \multicolumn{2}{|c|}{ Mixing/degassing cycle } & \multicolumn{2}{|c|}{ Cure schedule } & \multicolumn{2}{|c|}{ Post-cure schedule } \\
\hline & $\left({ }^{\circ} \mathrm{C}\right)$ & (h) & $\left({ }^{\circ} \mathrm{C}\right)$ & $(\min )$ & $\left({ }^{\circ} \mathrm{C}\right)$ & (h) & $\left({ }^{\circ} \mathrm{C}\right)$ & $(\mathrm{h})$ \\
\hline $\begin{array}{l}\text { DER } 332 \\
\text { DER } 337\end{array}$ & 80 & $>1$ & 80 & $\sim 60$ & 120 & 16 & 250 & 2 \\
\hline $\begin{array}{l}\text { DER } 661 \\
\text { DER } 662\end{array}$ & 140 & $>1$ & 140 & $\sim 45$ & 140 & 16 & 200 & 2 \\
\hline $\begin{array}{l}\text { DER } 664 \\
\text { DER } 667\end{array}$ & 160 & $>1$ & $>160$ & $\sim 20$ & 160 & 16 & 200 & 2 \\
\hline
\end{tabular}

mathematically as follows:

$$
\phi=\frac{C}{\mathrm{~d} C / \mathrm{d}(a / D)}
$$

At least six SEN specimens with varying crack lengths were fractured for each material. The cracks were introduced by cutting a notch using a jeweller's saw then hammering in a razor blade which had been immersed in liquid nitrogen. The chilling facilitates the propagation of a sharp crack in front of the tip of the razor blade. Three-point bending tests were performed using a screw-driven Instron (Model 1125) at a rate of $2.12 \mathrm{~mm} \mathrm{sec}^{-1}$. A Nicolet 2090 digital oscilloscope was used to capture the load-time traces. The initial crack length of each fractured specimen was measured using an optical microscope. An HP-86 desktop computer was programmed to integrate the load-time traces, to calculate $\phi$ values (using measured crack lengths), plot $U / B D$ against $\phi$, and determine the slopes of the $U / B D$ against $\phi$ curves using a least squares fit. The value of $G_{I C}$ is simply the slope of these curves.

\subsection{Tensile dilatometry}

Deformation mechanisms were determined using a tensile dilatometry technique modelled after that used by Bucknall [21], except that a constant displacement rate was used. Details of this technique were given in Part 1 [1]. The deformation mechanisms of a material are ascertained by analysing the volume strain against elongational strain plot. In such plots, initially one typically sees an increase in volume strain due to the Poisson effect; thereafter, deformational processes such as voiding result in a further increase in the volume strain, whereas shear deformation results in a decrease in the volume strain. This decrease is an artefact of the technique and is not necessarily real. However, this modest decrease in volume strain is very useful for signalling the onset of shear banding processes (see [1]).

\subsection{Microscopy}

Volume strain measurements are useful in identifying volume-increasing and volume-conserving processes. However, the application of several microscopy techniques is necessary to elucidate specific deformation mechanisms (see Part 2 [2]). Furthermore, the occurrence of specific deformation mechanisms is clearly dependent upon the stress state. Therefore, several fractography techniques were employed to investigate the nature of the process zone in fractured SEN specimens. These techniques included observa- tions of the fracture surfaces using scanning electron microscopy (SEM) and of the zones beneath the fracture surfaces using several transmission optical microscopy (OM) techniques. The major tool for SEM analysis was an ISI Super II scanning electron microscope. SEM specimens were coated with a thin film of $\mathrm{Au}-\mathrm{Pd}$ by sputtering. A Zeiss optical microscope was used to examine thin sections of material removed from planes perpendicular to the fracture surface. These thin sections were prepared using a petrographic polishing technique. Details of these techniques were given in Part 2 [2].

\section{Results and discussion}

\subsection{Cross-link density}

As discussed in Section 2, $M_{\mathrm{nc}}$ may be determined using the theory of rubber elasticity or by the empirical relation proposed by Nielsen [15]. Results for neat resins are shown in Table IV. Fig. 3 is a plot of $T_{\mathrm{g}}$ against the monomer molecular weight for the neat and elastomer-modified resins. Both methods indicate an increase in $M_{\mathrm{nc}}$ with increasing monomer molecular weight. LeMay and Kelley [22] have reported similar results in their work with DGEBA/DDS epoxies.

\subsection{Fracture toughness}

Fracture toughness values are determined in terms of $G_{\mathrm{IC}}$ using SEN specimens in a three-point-bend geometry. This method involves measuring the energy to break for several specimens of varying crack lengths (hence various values of $\phi$ ) for each type of material. The energy per unit cross-sectional area $(U / B D)$ values are plotted against $\phi$. These data are fitted to a

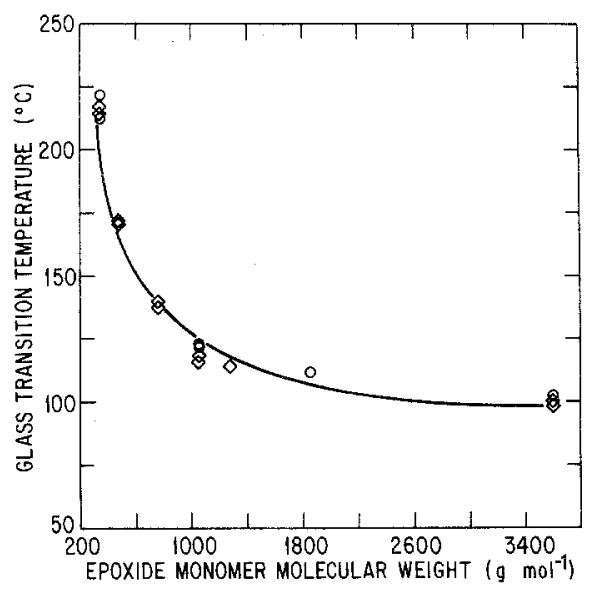

Figure $3 \mathrm{~A}$ plot of $T_{\mathrm{g}}$ against epoxide monomer molecular weight. The glass transition temperature initially decreases rapidly with increasing monomer molecular weight. $(\diamond)$ Elastomer-modified resins, (O) neat resins. 
TABLE IV Molecular weight between cross-links

\begin{tabular}{lccccc}
\hline Formulation & $\begin{array}{l}\text { Epoxide MW } \\
\left(\mathrm{g} \mathrm{mol}^{-1}\right)\end{array}$ & $\begin{array}{l}G_{\mathrm{e}} \\
\left(\mathrm{dyn} \mathrm{cm}^{-2}\right)\end{array}$ & $\begin{array}{l}M_{\mathrm{c}} \text { from } G_{\mathrm{e}} \\
\left(\mathrm{g} \mathrm{mol}^{-1}\right)\end{array}$ & $\begin{array}{l}T_{\mathrm{g}} \\
(\mathrm{K})\end{array}$ & $\begin{array}{r}M_{\mathrm{c}} \text { from } T_{\mathrm{g}} \\
\left(\mathrm{g} \mathrm{mol}^{-1}\right)\end{array}$ \\
\hline DER 332/DDS & $334-352$ & $1.3 \times 10^{8}$ & 305 & 493 & 302 \\
DER 661/DDS & $950-1150$ & $2.8 \times 10^{7}$ & 1160 & 393 & 1350 \\
DER 664/DDS & $1750-1950$ & $2.0 \times 10^{7}$ & 1600 & 378 & 2800 \\
DER 667/DDS & $3200-4000$ & $7.0 \times 10^{6}$ & 4350 & 373 & 4300 \\
\hline
\end{tabular}

straight line by the method of least squares. The slope of this line is the $G_{\mathrm{IC}}$ of the material tested.

Fig. 4 illustrates the large differences in the slope (hence $G_{\mathrm{IC}}$ values) of the elastomer-modified materials and the relatively small slopes of the neat epoxies. These differences can be more clearly seen in Fig. 5 which is a plot of $G_{\mathrm{IC}}$ against the monomer molecular weight for the neat epoxies as well as for the elastomer-modified materials. These results clearly show that the inherent fracture toughness of the neat epoxies is only a weak function of the monomer molecular weight. The values of $G_{I C}$ for the neat epoxies are in the same range as those reported by Scott et al. [12] on aliphatic amine-cured epoxies and similar to values reported by Cherry and Thompson [11]. However, more important is the result that the fracture toughness of the elastomer-modified epoxies is a relatively strong function of the monomer molecular weight. Therefore, the toughenability of a DGEBA epoxy by elastomeric addition depends upon the cross-link density of the epoxy matrix. The lower the cross-link density, the greater the toughenability.

The toughening effect may be understood in terms of the size of the process zone which blunts the sharp crack. Irwin [23] developed the concept of a formalized process zone which is inversely related to the squared power of the yield stress for a given material. This concept involves two equations, one for the plane strain case and one for the plane stress case:

for plane stress

$$
R_{\mathrm{p}}=\frac{1}{2 \pi}\left(\frac{K_{\mathrm{IC}}}{\sigma_{\mathrm{y}}}\right)^{2}=\frac{E G_{1 \mathrm{C}}}{2 \pi \sigma_{\mathrm{y}}^{2}}
$$

for plane strain

$$
R_{\mathrm{p}}=\frac{1}{6 \pi}\left(\frac{K_{\mathrm{IC}}}{\sigma_{\mathrm{y}}}\right)^{2}=\frac{E G_{\mathrm{IC}}}{6 \pi \sigma_{\mathrm{y}}^{2}}
$$

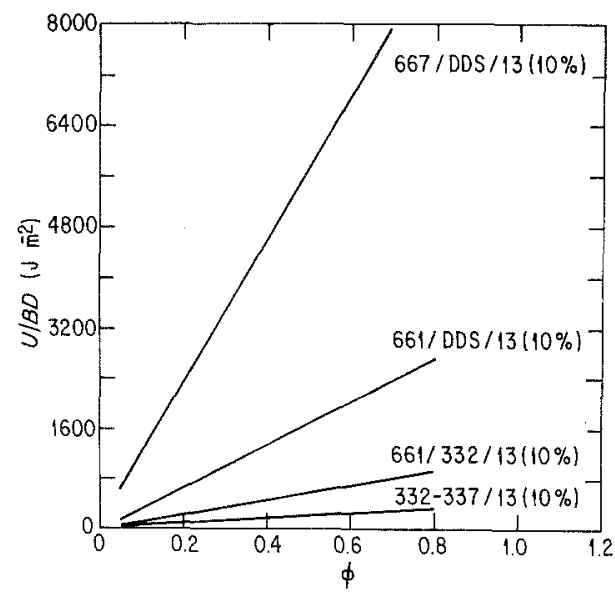

Figure $4 U / B D$ plotted against $\phi$ for several epoxies. Note the large differences in the slopes of the curves. where $R_{\mathrm{p}}$ is the radius of the formalized process zone. These equations suggest that any means of reducing the yield stress should result in an increase in process zone size and greater toughness. Table $\mathrm{V}$ contains the calculated and measured process zone sizes. Indeed, Irwin's equations appear to give reasonable estimations of the process zone sizes. However, this approach does not attempt to describe how these materials are toughened. Clearly, an analysis of the micromechanical deformation mechanisms is needed to understand the energy absorbing processes which provide toughness enhancement.

\subsection{Tensile dilatometry}

Volume dilation techniques have been used to elucidate the toughening mechanisms in thermoplastics. Bucknall [21] has found a large increase in volume strain when testing high-impact polystyrene and concluded that massive crazing was the major energy dissipation mechanism. Hooley et al. [24] have shown that polymethylmethacrylate can be toughened by the addition of rubber. They used a volume-strain technique to show that the slope of the volume-strain curve decreased upon rubber modification. They interpreted this result to mean that a shear deformation process is responsible for the toughening effect. Maxwell and Yee [25] used a volume dilation technique to determine that crazing was a major energy consuming mechanism in elastomer-modified polyphenylene oxide/polystyrene blends. Their transmission electron micrographs from deformed specimens provided conclusive evidence of crazing in these systems. This very same technique was used on piperidine-cured CTBN modified epoxies in a previous paper [1].

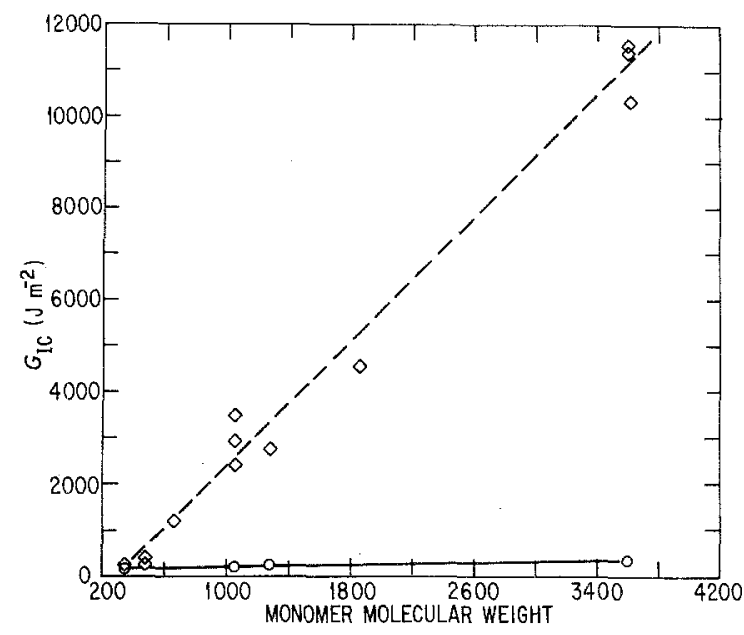

Figure 5 Fracture toughness increases modestly with increasing monomer molecular weight for neat epoxies. However, the fracture toughness of the rubber-modified epoxies increases dramatically with increasing epoxide monomer molecular weight. $(\diamond)$ Elastomer-modified resins; $(0)$ neat resins. 


\begin{tabular}{llccccc}
\hline $\begin{array}{l}\text { DGEBA } \\
\text { resin }\end{array}$ & $\begin{array}{l}E \\
\text { (MPa) }\end{array}$ & $\begin{array}{l}G_{\mathrm{IC}} \\
\left(\mathrm{Jm}^{-2}\right)\end{array}$ & $\begin{array}{l}\sigma_{\mathrm{y}} \\
(\mathrm{MPa})\end{array}$ & $\begin{array}{l}R_{\mathrm{p}} \\
\text { plane stress } \\
(\mu \mathrm{m})\end{array}$ & $\begin{array}{l}R_{\mathrm{p}} \\
\text { plane strain } \\
(\mu \mathrm{m})\end{array}$ & $\begin{array}{l}R_{\mathrm{p}} \\
\text { measured } \\
(\mu \mathrm{m})\end{array}$ \\
\hline DER 332 & 3360 & 162 & - & - & - & - \\
DER 661 & 3360 & 201 & 96.1 & 12 & 4 & - \\
DER 667 & 3360 & 326 & 85.6 & 24 & 8 & - \\
332/CTBN & 3000 & 242 & - & - & - & 62 \\
661/CTBN & 3000 & 3000 & 81.5 & 216 & 72 & 500 \\
667/CTBN & 3000 & 11400 & 73.3 & 1013 & 500 & - \\
\hline
\end{tabular}

Notes: DER 332 materials fractured (did not yield) in tensile testing; neat DER 661 and DER 667 epoxies did not exhibit detectable process zones.

In this study, the volume dilation experiments were again performed on several neat epoxies and their corresponding elastomer-modified versions to identify the toughening mechanism(s) when present. Our previous work [1] had shown that a cross-head rate of $25.4 \mathrm{~mm} \mathrm{sec}^{-1}$ is optimal to differentiate between the deformation behaviour of the neat and elastomermodified epoxies. Therefore, only this single crosshead rate is used in this study. These experiments also provide stress-strain data.

Stress-strain plots for DER332/DDS and DER332/ DDS/CTBN materials are not shown because these materials failed in a brittle manner (less than 1\% strain to failure). Measurements of volume strain against longitudinal strain only exhibited a monotonic increase, probably due solely to the Poisson's effect. These results do not provide insight into the deformation mechanisms except to indicate the absence of anelastic or shear deformation processes. These results are consistent with the fracture toughness results which indicated that both the neat and elastomer-modified versions of this highly cross-linked epoxy have poor resistance to crack propagation.

Fig. 6 is a plot of stress against strain and volume strain against longitudinal strain for the DER661/ DDS and DER661/DDS/CTBN epoxies. The molecular weight between cross-links of the DER 661-based materials is three times greater than that of the DER 332-based materials. This reduction in cross-link density increases ductility and a yield point is exhibited.

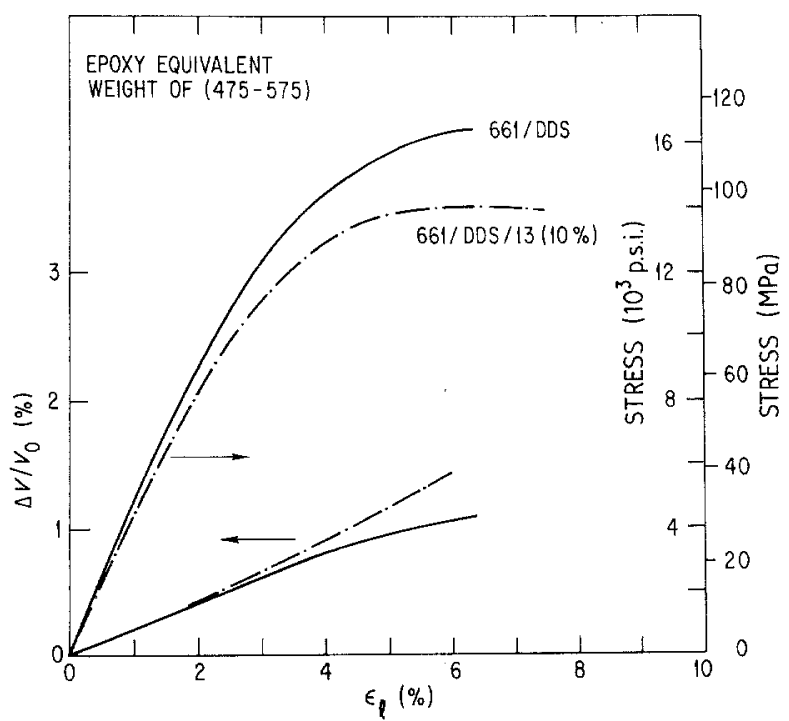

Figure 6 Tensile dilatometry results for the DER 661/DDS and the DER 661/DDS/CTBN epoxies. An additional volume strain increase is observed in the CTBN modified epoxy.
The incorporation of a second, soft, elastomeric phase decreases the stress required for yielding and reducing the Young's modulus, as expected. The volume strain curve of the neat epoxy indicates that this material deforms via a shearing process. By contrast, the corresponding curve for the elastomer-modified version indicates that an additional volume increasing mechanism is superimposed on the shear process. Based on our past experience (Part 1), we can surmise that this process is most likely voiding and not crazing. However, additional evidence is needed to support this statement (and is provided - see Section 3.4).

Fig. 7 shows plots of stress against strain and volume strain against longitudinal strain for the DER 667/DDS materials, the epoxy of lowest cross-link density studied in this investigation. The stress-strain curve of the neat epoxy indicates that the stress required for yielding is reduced, no doubt due to the reduction of cross-link density. The volume strain curve for the neat epoxy exhibits the now-familiar shear behaviour. The volume strain curve for the elastomer-modified version indicates that again, an additional volume increasing process is superimposed on the shear process. The next section presents additional evidence that this dilatative process is due to voiding.

\subsection{Microscopy}

The SEN fracture surfaces of elastomer-modified epoxies of increasing monomer molecular weight

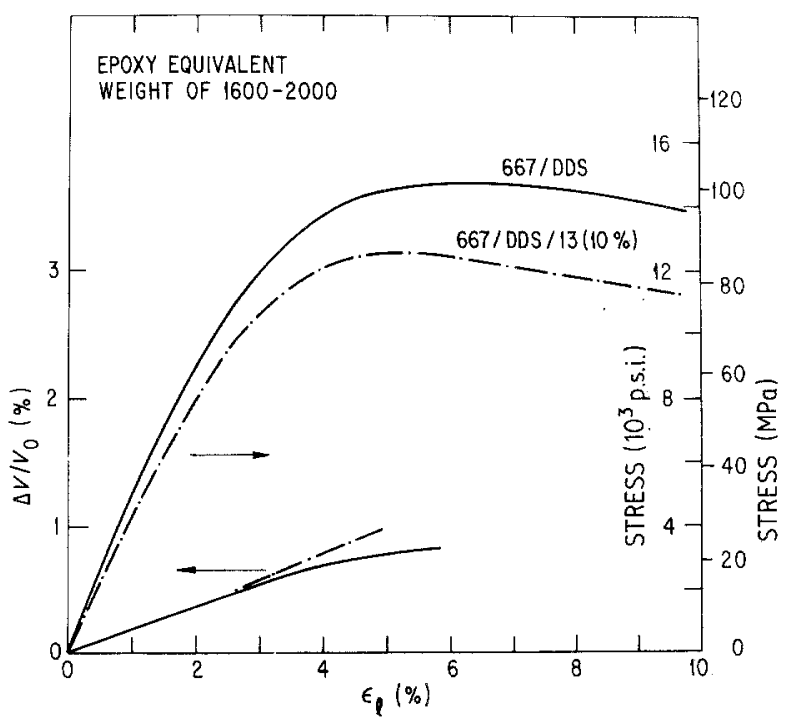

Figure 7 Tensile dilatometry results for the DER 667/DDS and the DER 667/DDS/CTBN epoxies. An additional volume strain increase is observed in the CTBN modified epoxy. 


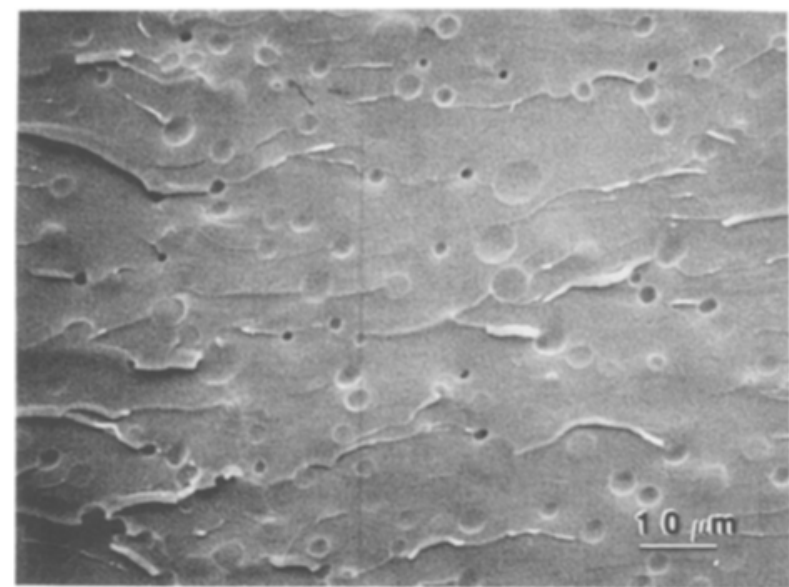

Figure 8 Scanning electron micrographs of the fracture surfaces of SEN specimens, near the region of the pre-starter crack arrest for DER 332/DDS/CTBN.

(DER 332, DER 661, and DER 667 based) are examined using scanning electron microscopy. These results are shown in Figs 8 to 10. The fracture surface of the most highly cross-linked material (DER 332based) contains very shallow voids with circular outlines (see Fig. 8). This scanning electron micrograph was taken at the region of the specimen where the starter crack had arrested and then was propagated during loading in the three-point bend test. The relative smoothness of the fracture surface seen in this micrograph suggests that no significant plastic deformation has occurred near the fracture surface. Clearly, the rubber particles had cavitated and fractured; yet, the fracture toughness is quite poor. The correlation between the lack of toughness and the lack of a significant process zone is evident, and will be discussed in the concluding section. The deformation of the rubber particles has evidently contributed very little to the fracture toughness.

Fig. 9 shows a scanning electron micrograph of the fracture surface of the SEN specimen comprised of the DER 661-based material. This micrograph shows that the voids are, in comparison with those in Fig. 8, deeper and more elliptical. These results indicated that the rubber particles had cavitated and were subjected

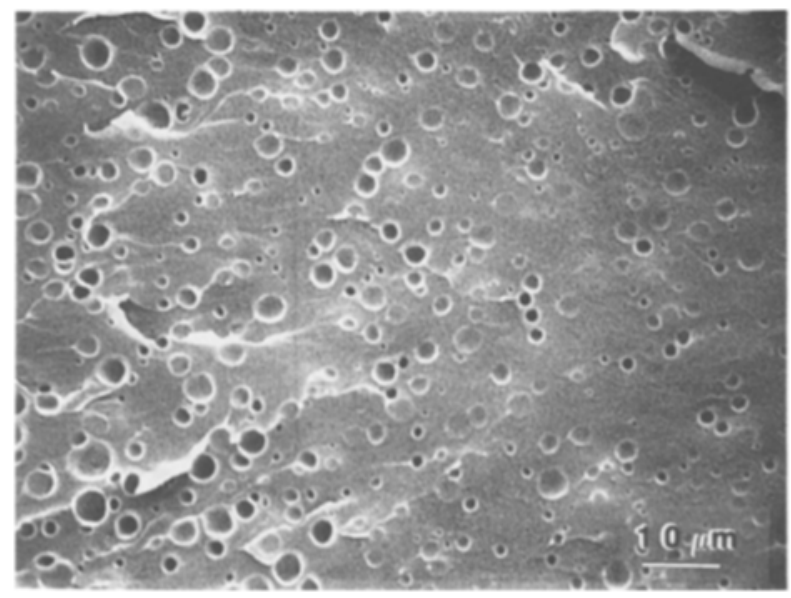

Figure 9 Scanning electron micrographs of the fracture surfaces of SEN specimens, near the region of the pre-starter crack arrest for DER 661/DDS/CTBN.

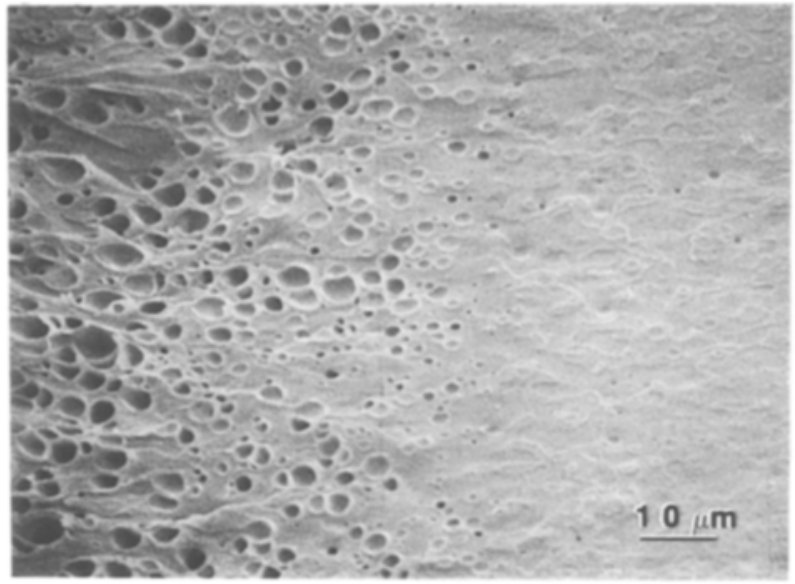

Figure 10 Scanning electron micrographs of the fracture surfaces of SEN specimens, near the region of the pre-starter crack arrest for DER 667/DDS/CTBN.

to a shear deformation. Note that there is no evidence for debonding of the elastomer particles. This micrograph was taken in the region where the starter crack had arrested and a stress-whitened zone had formed prior to unstable fracture. The stress whitening results from the scattering of light by voided rubber particles formed not just at the surface but also in a subsurface zone. The formation of this process zone correlates well with toughening effects seen in elastomer-modified epoxies.

A scanning electron micrograph of the fracture surface of an SEN specimen comprised of DER 667/ DDS/CTBN is shown in Fig. 10. This elastomermodified epoxy has the lowest cross-link density of all of the epoxies studied in this investigation. This micrograph clearly shows that the rubber particles have cavitated and have been sheared severely in the region beyond the starter crack. This region has stresswhitened and the zone extends from the line where the starter crack arrested all the way to the opposite edge of the SEN specimen. Also, visual inspection of this specimen reveals that the sides near the fracture surface are concave in shape, thus indicating the formation of plane stress fracture zones and is clearly another sign of increased toughness. This material possesses the largest process zone and the highest $G_{\mathrm{IC}}$.

The nature and extent of the subsurface process zone formed ahead of the crack tip may be elucidated through the use of transmission optical microscopy. In our previous work (Part 2 [2]) we presented micrographs of the subsurface process zone using bright field and polarized light. The bright-field imaging accentuates the cavitated rubber particles which, being efficient light-scatters, appear almost black. The crossed-polarized light renders visible the shear bands which are composed of highly oriented birefringent material. Fig. 11 is an optical micrograph of the region beneath the fracture surface of an SEN specimen of the DER332/DDS/CTBN material. The examined section is rather thick, $\sim 25 \mu \mathrm{m}$, but still there is no evidence of voided rubber particles (which should be dark in appearance). Upon careful examination (and using polarized light), one may observe a small birefringent region about one rubber particle diameter in 


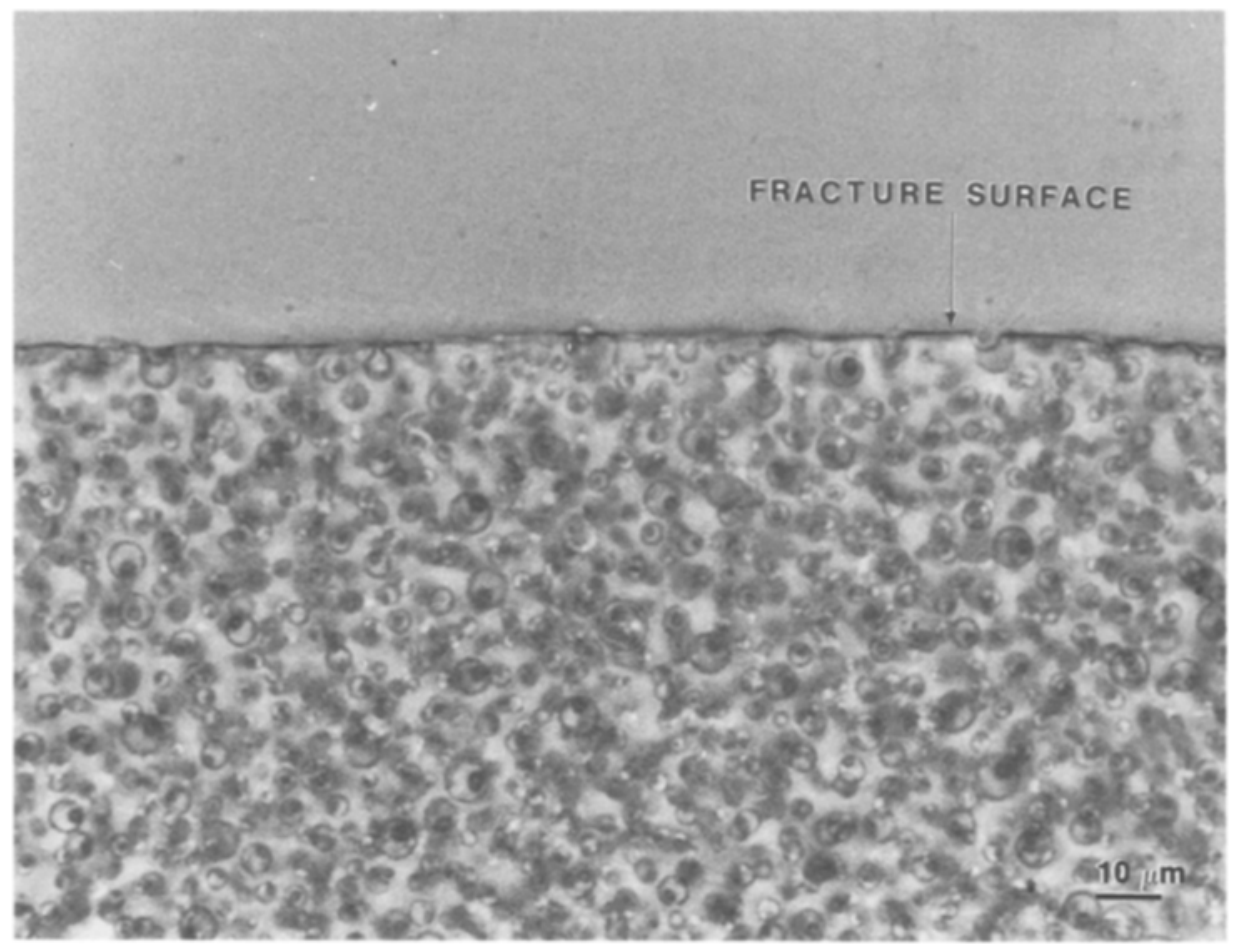

Figure I/ An optical micrograph, taken under crossed polarized light, of the region below the fracture surface of a DER 332/DDS/CTBN SEN specimen. There is little, if any, evidence of a process zone.

thickness just below the fracture surface. This small region is the process zone which formed as the crack was being loaded. Fig. 12 is an optical micrograph of the subsurface region of an SEN specimen composed of the less cross-linked DER661/DDS/CTBN material. The cavitated particles can be seen even in the polarized light. A significant number of birefringent shear bands may be seen connecting these voided rubber particles. This region extends several tens of micrometres beneath the fracture surface.
Fig. 13 is an optical micrograph of the subsurface of the SEN specimen composed of the toughest material tested in this study (DER667/DDS/CTBN). The size of the process zone is enormous. At this magnification, the zone extends well beyond the field of view. The size of the cavitated particles is largest near the fracture surface. This observation can be explained by the greater hydrostatic tensile stress that occurs in the plane of the advancing crack tip. The volume and density of shear bands is also significantly

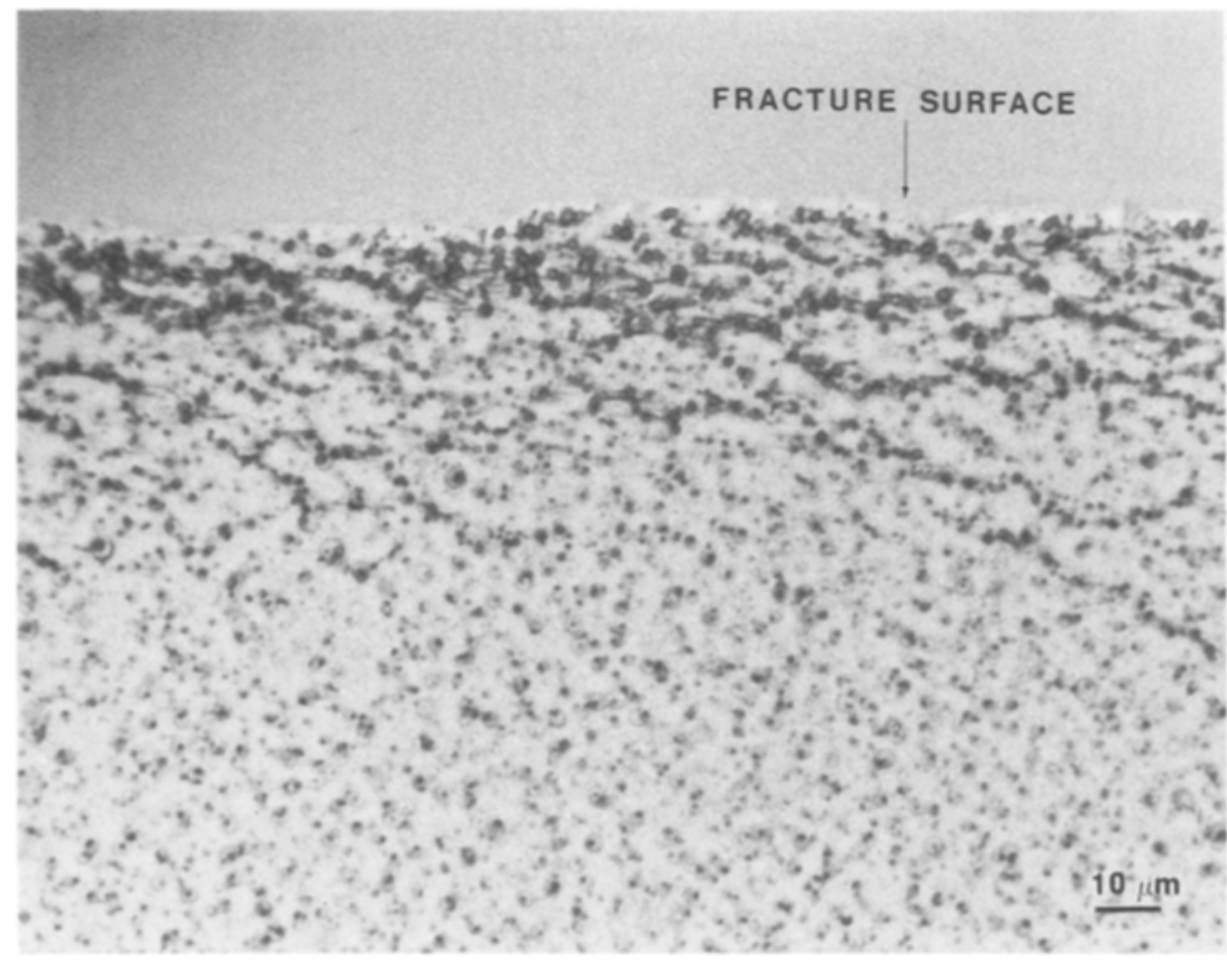

Figure 12 An optical micrograph, taken under crossed polarized light, of the region below the fracture surface of a DER $661 / D D S / C T B N$ SEN specimen. The process zone consists of voided rubber particles connected by shear bands. 


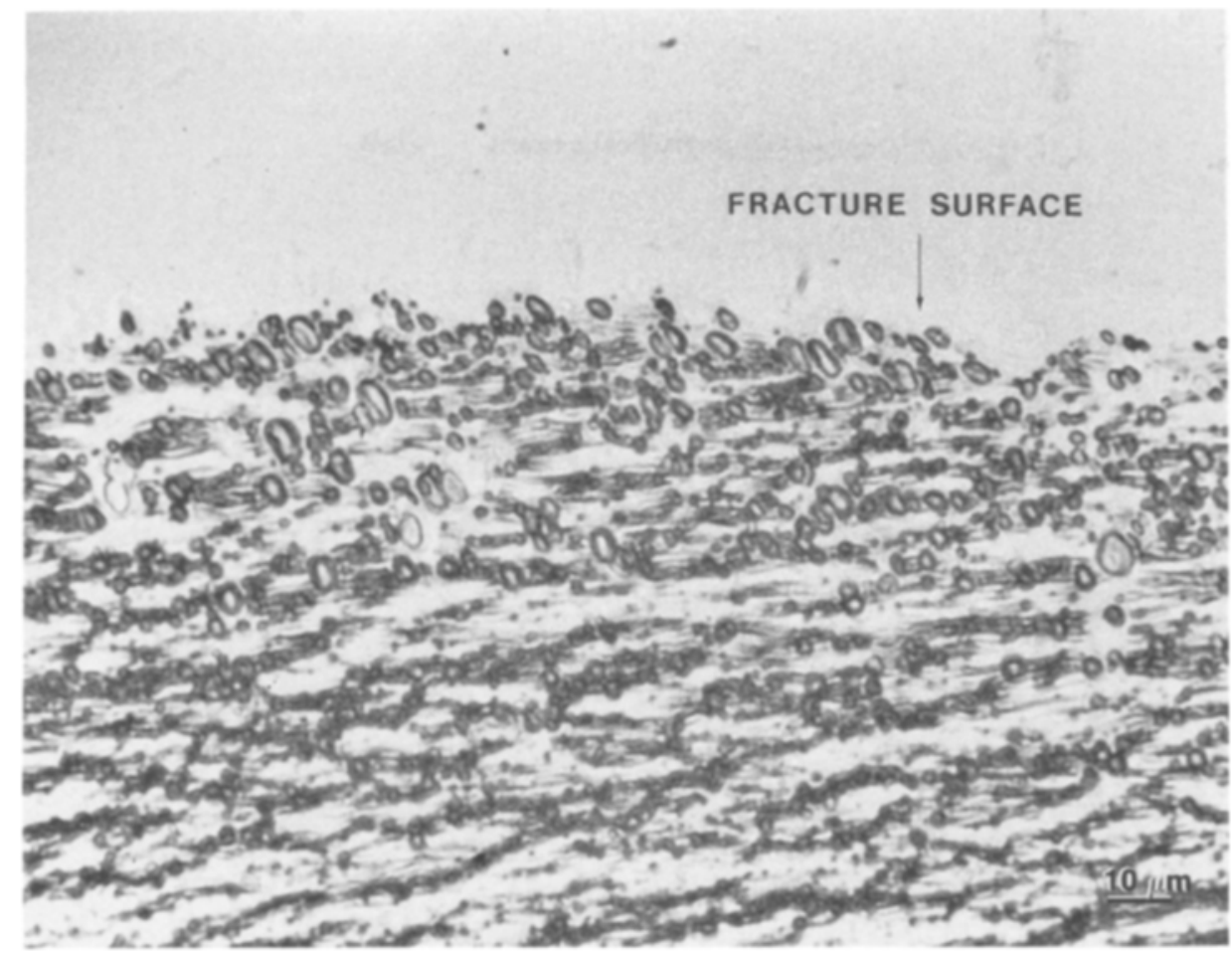

Figure 13 An optical micrograph, taken under crossed polarized light, of the region below the fracture surface of a DER 667/DDS/CTBN SEN specimen. The entire process zone cannot be contained in one micrograph (at this same magnification).

larger than the moderately toughened DER661/DDS/ CTBN material. Clearly, the formation of such a zone must have consumed a significant amount of energy.

\section{Conclusions}

The toughening mechanisms of elastomer-modified epoxies was deduced in our previous works $[1,2]$. Toughness enhancement was thought to be principally due to two energy dissipating mechanisms at the crack tip. The first mechanism dissipates bulk strain energy and relieves the triaxial constraint via cavitation of the rubber particles. The second mechanism dissipates shear strain energy through the formation of shear bands which is enhanced by the voided rubber particles. The present results support our previous conclusions.

This investigation revealed that the ability of the matrix to yield plays a fundamental role in determining whether these toughening mechanisms can be active. Epoxies with a low cross-link density exhibit greater ductility and correspondingly, greater toughenability. An important point is that simply adding a soft elastomeric phase does not guarantee enhanced toughness. However, the addition of a soft elastomeric phase to a ductile matrix (albeit with low fracture toughness in the unmodified state) results in the desired toughness enhancement. The toughening mechanism is identical to the previously studied piperidine-cured, CTBN-modified DGEBA epoxies; voiding and shear banding are again the energy dissipative processes.

The effect of reducing the cross-link density has been proposed to be an increase in the mainchain mobility which results in increased ductility. Of course, increasing the temperature also increases main chain mobility and the reduction of the glass transition temperature is effectively raising the test temperature relative to $T_{g}$. Therefore, fracture toughness measurements at temperatures relative to $T_{\mathrm{g}}$ are necessary in order to separate out the $T_{\mathrm{g}}$ effect. However, there are two examples which indicate that this increased ductility is not just a $T_{\mathrm{g}}$ effect. First, the $T_{\mathrm{g}} \mathrm{s}$ of DER 664/CTBN and DER 667/CTBN differ by only $5^{\circ} \mathrm{C}$ whereas the fracture toughness values differ by a factor of three. Secondly, the rather well-studied piperidine-cured, elastomer-modified epoxies have shown enhanced toughness when bisphenol-A (BPA) was used as a matrix modifier even though the $T_{g}$ of the latter is actually higher. This result has been reported by a number of authors $[1,7,26]$ including ourselves. It is believed that BPA acts as a chain extender. There are several examples of commercial linear polymers that possess $T_{\mathrm{g}} \mathrm{s}$ greater than $200^{\circ} \mathrm{C}$ and yet exhibit a very ductile behaviour when tested in uniaxial tension at room temperature. We contend that as long as the matrix is ductile, then it can be toughened by the addition of a soft elastomeric phase, and that the toughenability increases with the ability to shear yield and cold draw.

\section{Acknowledgements}

The authors thank Dr N. Johnston of NASA-Langley, the Contract Monitor of this work, for his encouragement and patience. This work was partially supported by NASA contract No. NASI-16132. They also acknowledge the assistance of the following scientists at the General Electric Corporate Research and Development Center: Mr J. Grande for performing the optical microscopy work; Dr M. T. Takemori, Dr D. S. Matsumoto, Mr T. Morrelli, and Ms L. M. Carapellucci for stimulating discussions; and Dr A. R. 
Schultz and Mrs A. L. Young for their assistance with the DSC $T_{\mathrm{g}}$ measurements.

\section{References}

1. A. F. YEE and R. A. PEARSON, J. Mater. Sci. 21 (1986) 2462.

2. R. A. PEARSON and A. F. YEE, ibid. 21 (1986) 2475.

3. W. D. BASCOM, R. L. COTTINGTON, R. L. JONES and P. PEYSER, J. Appl. Polym. Sci. 19 (1975) 2425.

4. W. D. BASCOM and R. L, COTTINGTON, J. Adhesion 7 (1976) 333

5. A. J. KINLOCH, S. J. SHAW, D. A. TOD and D. L. HUNSTON, Polymer 24 (1983) 1341.

6. Idem, ibid. 24 (1983) 1355.

7. A. J. KINLOCH and D. L. HUNSTON, J. Mater. Sci. Lett. 5 (1986) 909.

8. C. MEEKS, Polymer 15 (1974) 675.

9. T. D. CHANG and J. O. BRITTAIN, Polym. Engng Sci. 22 (1982) 1228.

10. J. N. SUltan, R. C. LIABLE and F. J. McGARRY, Appl. Polym. Symp. 16 (1971) 127.

11. W. B. CHERRY and K. W. THOMPSON, J. Mater. Sci. 16 (1981) 1913.

12. J. M. SCOTT, G. M. WELLS and D. C. PHILLIPS, ibid. 15 (1980) 1436

13. A. J. EVANS, Z. B. AHMAD, D. G. GILBERT and P. W. R. BEAUMONT, Acta Metall. 34 (1986) 79.

14. H. LEE and K. NEVILLE, "Handbook of Epoxy Resins" (McGraw-Hill, New York, 1967).

15. L. E. NiELSEN, Rev. Makomol. Chem. C3(1) (1969) 77.
16. J. D. FERRY, "Viscoelastic Properties of Polymers", 3rd Edn. (Wiley, New York, 1980).

17. V. Bellenger, J, Verdu and E. MOREL, J. Polym. Sci. B 25 (1987) 1219.

18. E. Plati and J. G. Williams, Polym. Engng Sci. 15 (1975) 470

19. P. E. REED, "Impact Performance of Polymers", in "Developments in Polymer Fracture-1" (Applied Science, London, 1977) pp. 121-52

20. J. G. WILliams, "Stress Analysis of Polymers" (Wiley, New York, 1973).

21. C. B. BUCKNALL, "Toughened Plastics" (Applied Science, London, 1977).

22. J. D. LeMAY and F. N. KELLEY, "Structure and Ultimate Properties of Epoxy Resins", in "Advances in Polymer Science", Vol. 78 (Springer-Verlag, New York, 1986) pp. 11548.

23. G. R. IRWIN, Appl. Mater. Res. 3 (1964) 65.

24. C. T. HOOLEY, D. R. MOORE, M. WHALE and M. J. Williams, Plast. Rub. Proc. Appl. 1 (1981) 345.

25. M. A. MAXWELL and A. F. YEE, Polym. Engng Sci. 21 (1981) 205

26. C. K. RIEW, E. H. ROWE and A. R. SIEBERT, in "Advances in Chemistry Series, No. 154, Toughness and Brittleness of Plastics" (American Chemical Society, Washington, 1976) p. 326.

Received 8 April

and accepted 7 September 1988 